\title{
Bakterier renser drikkevand - ny metode til fjernelse af BAM undervejs
}

Af Maria Sommer Holtze og Jens Aamand, Danmarks og Grønlands Geologiske Undersøgelse (GEUS).

I hver femte af de danske drikkevandsboringer er vandet forurenet med stoffet BAM, der stammer fra brug af pesticider. To ufarlige bakterier fundet $\mathrm{i}$ jord kan sandsynligvis fjerne BAM fra drikkevandet, inden det når frem til din vandhane.

Forestil dig, at din lokale vandværksmand står med en dåse i hånden. Han læser på mærkaten: "Frysetørret Aminobacter", inden han drysser det uskadelige pulver ned i vandværkets sandfilter. Mærkeligt tænker du måske. Men det er ikke så mærkeligt endda. Aminobacter er navnet på to nye bakterier fra dansk jord, der har den unikke egenskab, at de omdanner pesticidresten BAM til det rene ingenting - eller rettere til $\mathrm{CO}_{2}$ og vand. Bakterierne vil derfor kunne bruges som en naturlig og ufarlig vandrenser.

\section{BAM i grundvandet}

BAM i grundvandet stammer fra brugen af dichlobenil i sprøjtemidlerne Prefix og Casoron, der siden 1997 er forbudte at anvende i Danmark. Dichlobenil er anvendt til at bekæmpe ukrudt i haver, på stier og kirke-

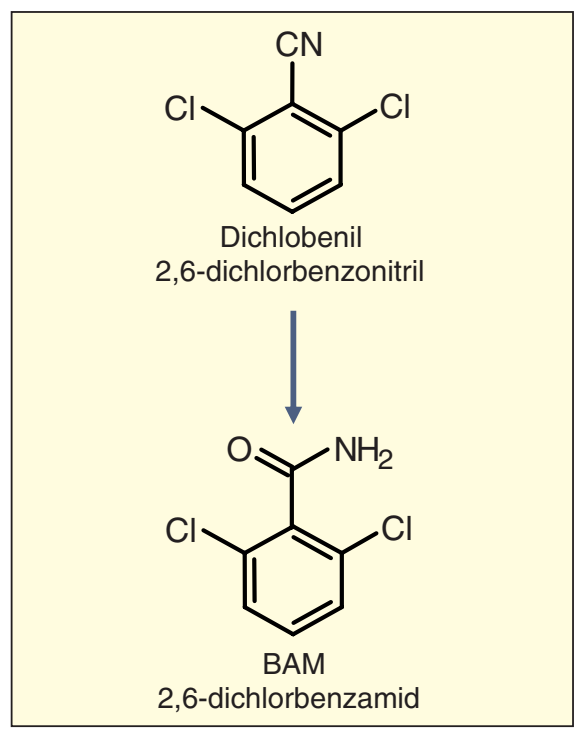

Kemiske formler for dichlobenil og BAM. (Grafik: Maria Sommer Holtze)

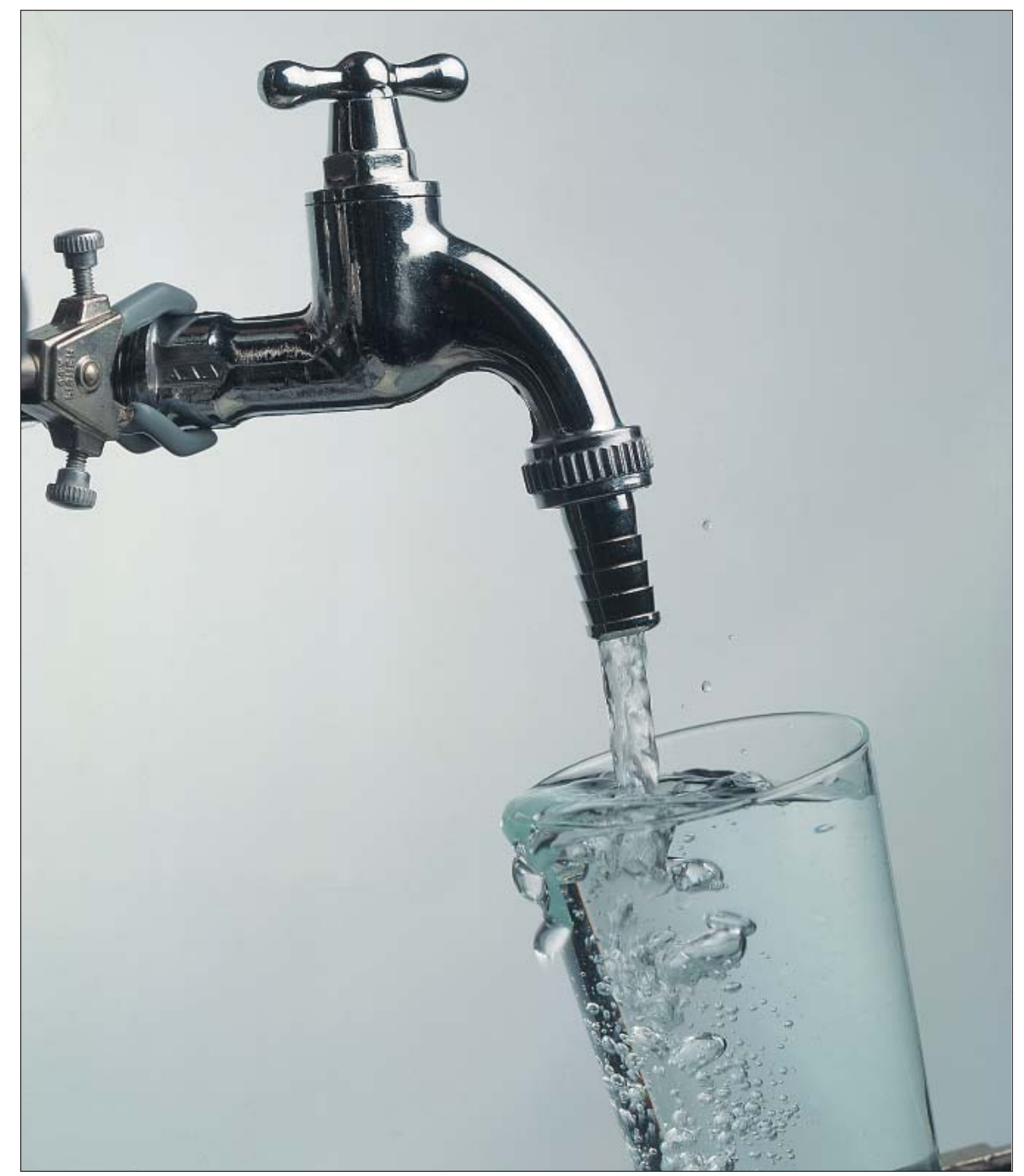

Hver femte drikkevandsboring er forurenet med stoffet BAM. (Foto: GEUS, Peter Warna-Moors)

gårde m.m. Landmændene brugte ikke dichlobenil på markerne, da det slår afgrøderne ihjel. Bakterierne i jord omdanner hurtigt dichlobenil til BAM, men da dichlobenil blev anvendt, kunne bakterierne ikke omdanne BAM videre $\mathrm{i}$ jorden. Med det næste regnskyl er det meste af det dannede BAM transporteret gennem jorden ned til grundvandet. Her ligger det mange steder endnu.

I overvågningen af det danske grundvand er der udtaget 5.851 prøver, der er analyseret for indholdet af BAM, og der er fundet BAM i næsten hver femte af disse prøver! Dette giver BAM en suveræn førsteplads i kampen om at være det forurenende stof, der oftest findes i det danske grundvand.
Hvorfor er BAM et problem?

I Danmark får vi $99 \%$ af vores drikkevand direkte fra grundvandet. Da indholdet af sprøjtemidler i drikkevand ifølge lovgivningen stort set skal være nul (maksimalt 0,1 mikrogram per liter), bliver mange drikkevandsboringer lukket pga. BAM, selvom stoffet i sig selv ikke er giftigt for mennesker. Det er imidlertid uvist, hvordan kroppen reagerer, hvis BAM indtages sammen med andre miljøfremmede stoffer, og om stoffet på sigt kan give kræft.

For drikkevandsforsyningen er BAM et stort problem, da der sjældent er andre steder at hente drikkevand. Nogle steder er der givet tilladelse til at rense vandet ved hjælp 
af et filter af såkaldt aktivt kul. Dette filter er dyrt at etablere og dyrt at drive, hvilket betyder dyrere vand til dig som forbruger. Nogle mener endda, at vandet ændrer smag ved denne rensning.

Fjernelse af BAM fra drikkevandet ved hjælp af bakterier er et billigt og grønt alternativ til denne rensning.

\section{Bakterier renser vandet}

På vandværkerne i Danmark bliver det oppumpede grundvand luftet, hvorefter det ledes videre til filtre med sand. Formålet med sandfiltrene er at fjerne naturligt forekommende uønskede stoffer såsom metan, svovlbrinte og jern, inden vandet bliver til drikkevand. BAM fjernes ikke i disse filtre, selvom der lever en del bakterier i filtrene. Ved at tilsætte frysetørrede Aminobacterbakterier formoder vi, at de fra deres faste plads i filtrene kan fjerne BAM fra vandet. Vores undersøgelser viser nemlig, at bakterierne er i stand til at fjerne BAM fra grundvand i laboratoriet.

\section{Fleksible bakterier}

De to bakterier, der kan fjerne (nedbryde) BAM, har vi fundet i forurenet jord fra hhv. Marstal og Hvidovre, hvor dichlobenil er anvendt indtil forbuddet i 1997. I jord er der ofte ikke næring nok til alle typer bakterier. Bakterier, der kan tilpasse sig udnyttelsen af nye typer næring, vil derfor have en større chance for at overleve. Selv giftige stoffer kan på denne måde blive nedbrudt af bakterier, som er i stand til at tilpasse sig og bruge giftstofferne som næring.

Tilpasningen af jordens bakterier til at

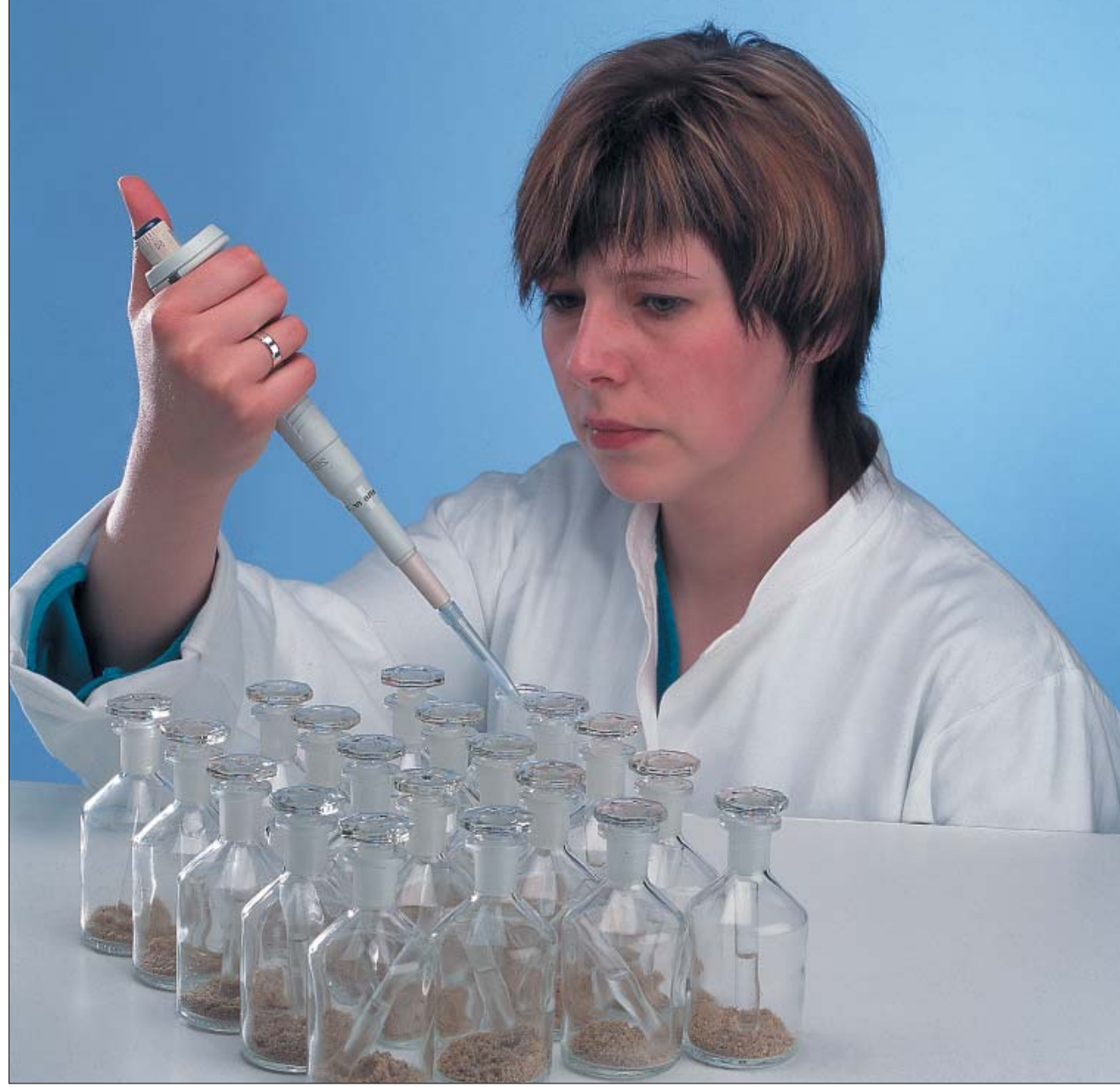

Det krcever mange arbejdstimer i laboratoriet at opnå en ren kultur af én bestemt bakterie fra en jordprøve. (Foto: GEUS, Peter Warna-Moors) udnytte nye typer næring tager tid. Hvor lang tid afhænger af, hvor besværlige stofferne er at gå til - og hvor anderledes stofferne er i forhold til de stoffer, bakteri-

\section{Bakterier fjerner BAM}

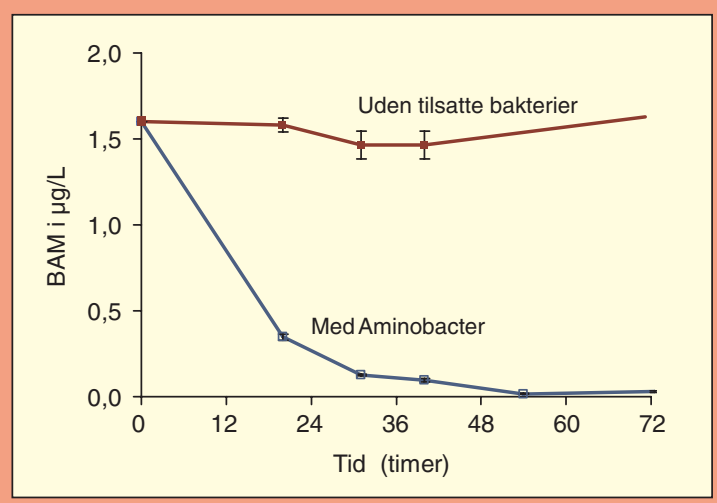

På figurens blå graf ser man, at bakterien Aminobacter fjerner det tilsatte BAM effektivt fra grundvandet. Efter to dage er koncentrationen lavere end 0,02 mikrogram pr. liter, hvilket er under de 0,1 mikrogram pr. liter, der højst må være $\mathrm{i}$ vandet, hvis det skal bruges til drikkevand. Kun få bakterier er $\mathrm{i}$ stand til at fjerne pesticider ved så lave koncentrationer i grundvand, da deres enzymer kun tændes ved højere koncentrationer. Hvis vi ikke tilsætter bakterien, forbliver BAM i grundvandet, som vist på den røde graf. Hvert punkt repræsenterer gennemsnittet af forsøg i tre flasker tilsat grundvand, BAM og evt. Aminobacter ved $10^{\circ} \mathrm{C}$. Desuden er standardafvigelserne angivet for hvert punkt. (Grafik: Maria Sommer Holtze) erne normalt udnytter som næring. Nogle miljøfremmede stoffer ligner simpelthen de naturlige stoffer mere end andre. Fx adskiller BAM sig fra det naturlige stof benzamid ved at have to klor-atomer påsat. Klor-atomerne forhindrer, at de enzymer, der nedbryder det naturlige stof benzamid, kan komme til at nedbryde stoffet, men enzymerne er formodentlig blot ændret i mindre grad for også at kunne nedbryde BAM. Hvor lang tid det tog bakterierne at få smag for BAM, ved vi ikke, men selv i dag har de en fordel af at kunne nedbryde BAM i de jorder, hvor der stadig ligger en rest dichlobenil eller BAM tilbage.

\section{Bakterierne er ufarlige}

De to bakterier, der fjerner BAM, tilhører slægten Aminobacter. Heldigvis ved vi, at denne gruppe bakterier ikke omfatter sygdomsfremkaldende bakterier, og at de ikke er i stand til at vokse ved $37^{\circ} \mathrm{C}$, som jo er vores legemstemperatur. Det er desuden vigtigt, at der kun er én type bakterier - eller at vi i det mindste kender alle bakterierne - i det pulver vandværksmanden drysser ud over sandfilteret. Kender vi ikke alle bakterierne, er der risiko for, at der er en sygdomsfremkaldende bakterie i pulveret.

\section{Fra laboratoriet til vandværket}

$\mathrm{Nu}$ står vi så i laboratoriet med bakterier, der kan fjerne BAM - tilmed i grundvand. Men hvad skal der til for, at det i stedet er 


\section{Isolering af BAM-elskende bakterier}

Fra at have en jord, hvor de naturlige bakterier kan nedbryde BAM, til at have bakterien i en helt ren kultur på bordet i laboratoriet, kan dervære lang vej. For at øge antallet af de bakterier, der kan nedbryde BAM, påbegyndte vi en såkaldt berigelse. De blå kugler i flaskerne symboliserer bakterier, der fjerner BAM. I flasken længst til venstre tilsættes jord til væske med BAM. Når bakterierne har fjernet al den tilsatte BAM, vil de bakterier, der kan leve afBAM, udgøre en større del af det samlede antal bakterier - det ses i den midterste flaske, at flere kugler er blå. I modsætning hertil vil de bakterier, der ikke kan spise BAM, udgøre en mindre del, da de fortyndes ud af opløsningen ved overførsel til ny væske med BAM.

Efter flere overførsler vil der stort set kun være de bakterier tilbage, der kan fjerne BAM - næsten alle kuglerne er blå i flasken til højre. Det er nu tid til at overføre en del af væsken til en agarplade for at få bakteriekulturen helt ren og således være sikker på, at

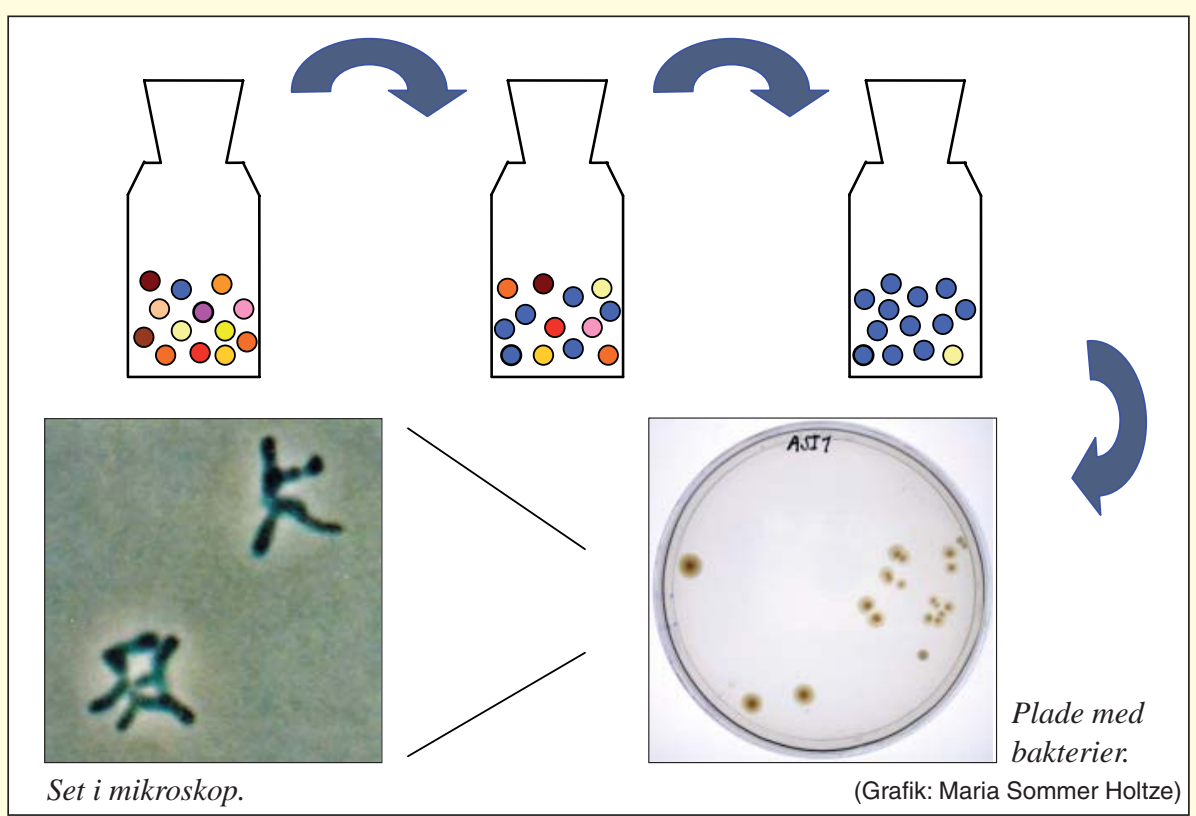

der blot er én type bakterie tilbage. På pladen ses bakterierne som store kolonier af mange bakterier. For at se de enkelte bakterier må man tage mikroskopet til hjælp, som vist på billedet til venstre. Denne fremgangsmåde i vores laboratorium har ført til, at der i dag kendes to bakterier, der kan leve af BAM: Aminobacter sp. ASI1 og Aminobacter sp. MSH1. vandværksmanden, der står med bakterierne i hånden? Vi skal nu undersøge, hvilke mængder bakterier vi tilsætter sandfilteret for at opnå en effektiv fjernelse af BAM. Vi skal sikre os, at BAM bliver fuldstændigt omdannet til $\mathrm{CO}_{2}$ og vand inden for den tid, vandet opholder sig i filteret. Evt. skal vandet være længere tid i sandfilteret, end det er tilfældet i dag. Desuden undersøger vi, om bakterierne kan overleve i et allerede eksisterende sandfilter i kampen med de andre bakterier om plads og næring. Og endelig skal vi sikre os, at bakterierne ikke bare løber gennem filteret til drikkevandsledningen og dermed ender i din vandhane frem for at blive i filteret.
Alt dette undersøger vi i øjeblikket i projektet PESTICON i samarbejde med vandværker i København (Københavns Energi), Odense, Hvidovre og Svendborg. Indtil videre giver projektet lovende resultater. Synet af vandværksmanden, der læser "Frysetørret Aminobacter" på mærkaten, inden han drysser pulveret ud over sandfilteret, ligger måske derfor slet ikke så langt ude i fremtiden.

Forslag til yderligere leesning: Miljøprojekt nr. 732 og 1000 fra Miljøstyrelsen

www.pesticon.dk

www.grundvandsovervaagning. $d k$
Denne artikel er tidligere bragt i Aktuel Naturvidenskab nr. 6-2006

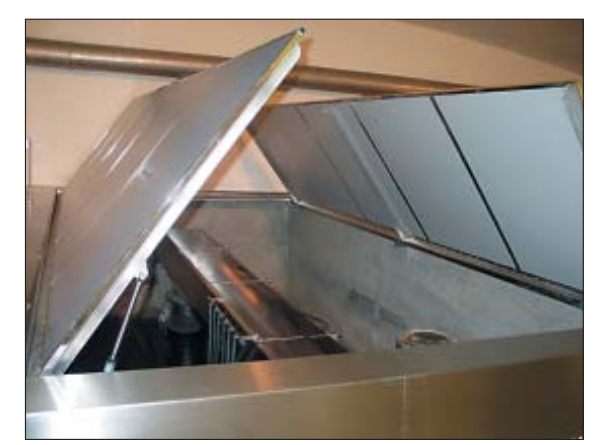

Et kig ned i et sandfilter på et vandvcerk. (Foto: Odense Vandselskab as) 